\title{
Accuracy Improvements for Cold-Start Recommendation Problem using Indirect Relations in Social Networks
}

\section{Fu Jie Tey}

National Taiwan University of Science and Technology

Tin-Yu Wu ( $\square$ tyw429@gmail.com )

NIU: National I-Lan University

Chiao-Ling Lin

National I-Lan University

Jiann-Liang Chen

National Taiwan University of Science and Technology

\section{Research}

Keywords: Social network, Indirect relation, Cold-start

Posted Date: December 31st, 2020

DOl: https://doi.org/10.21203/rs.3.rs-137823/v1

License: (a) (i) This work is licensed under a Creative Commons Attribution 4.0 International License.

Read Full License

Version of Record: A version of this preprint was published at Journal of Big Data on July 6th, 2021. See the published version at https://doi.org/10.1186/s40537-021-00484-0. 


\title{
Accuracy Improvements for Cold-Start Recommendation Problem using Indirect Relations in Social Networks
}

\author{
Tey Fu Jie ${ }^{1}$, Tin-Yu Wu ${ }^{2 *}$, Chiao-Ling Lin $^{3}$, Jiann-Liang Chen ${ }^{1}$ \\ 1. Department of Electrical Engineering, National Taiwan University of Science and Technology, Taiwan \\ 2. Department of Computer Science and Information Engineering, National Ilan University, Taiwan \\ ${ }^{3 .}$ Master Program of E-Learning for Multimedia and Network Communications, National Ilan University, Taiwan \\ E-mail: alexsword88@gmail.com; tyw@niu.edu.tw*; mmvstoii0603@gmail.com; Lchen@mail.ntust.edu.tw
}

\begin{abstract}
Recent advances on Internet applications have facilitated information spreading. Thanks to a wide variety of mobile devices and the burgeoning 5G networks, users gain access easily and quickly to information. Also, the great amount of digital information has contributed to the emergence of recommender systems that help information filtering. As the rise of mobile networks has pushed forward the growth of social media networks, users have gotten used to posting whatever they do and wherever they visit on the Web. Nevertheless, quick social media updates can make it difficult for users to find historical data. For this reason, this paper presents a social network-based recommender system. Our purpose is to build a user-centered recommender system to exclude the products that users are disinterested in according to user preferences and their friends' shopping experiences so as to make recommendations effective. There is normally no corresponding reference value for new products or services, so we use the indirect relations between friends and "friends' friends" as well as sentinel friends to improve the recommendation accuracy. Our proposed mechanism has been proven efficient in enhancing recommendation accuracy.
\end{abstract}

\section{Keywords- Social network, Indirect relation, Cold-start}

\section{INTRODUCTION}

Thanks to the development of modern technology and the wide-spread use of mobile devices, people have convenient access to information nowadays and recommender systems are therefore extensively adopted in various commercial and educational fields. Whenever a user is interested in a specific product or service, he or she may first ask his/her friends about their shopping experiences and then find more information on the Internet. Nevertheless, it is very time-consuming to read the customer reviews of all items listed in the search results list. For example, to find the best restaurants in the designated area, users may follow websites like Google Map to check the comments and star ratings one by one. However, those reviews with star ratings but no comments will be doubted.

Recommender systems have been applied in various fields, like tourism industry, food industry, and film industry and so on[1][2]. There are many restaurants and movies, but not everyone meets your need. Everyone has different preferences: it could be the prices, the brands or the specifications. In such a context, we would like to build a user-centered, personalized recommender system. To combine social network sites, like Facebook, Twitter and Yelp, with recommender systems, our proposed scheme is able to learn user preferences based on friends' most recent posts and relevant shopping experiences. While sharing information with friends, users not only facilitate the spread of messages, but also help promote the products or services and attract more consumers. According to the user preference data, the recommender systems can make follow-up recommendations and users can save time to find ideal targets. Since there is no rating or review for new products or services, we will particularly deal with the coldstart problem and establish a review procedure so that users can find suitable products or services quickly and accurately. $[3][4][5]$

This paper is organized as follows. Section 2 describes the background and related work, including recommender systems, Web 2.0 and social networks. Section 3 states the problem and how to solve it. Section 4 gives the experiment and data analysis. Last of paper is results present in Section 5 and the discussion in Section 6.

\section{BACKGROUND AND RELATED WORK}

This section introduces recommender systems, Web 2.0 and social networks.

\section{A. Recommender Systems}

According to Resnick and Varian (1997), recommender systems, for user convenience, can filter information based on user preferences and provide information to users that they might be interested in. Schafer et al. (2001) believe that advantages of recommender systems include Converting Browsers into Buyers, Increasing Cross-sell and Building Loyalty.

Traditional recommender systems require explicit or implicit user interactions. Explicit method relies on explicit user ratings while implicit ones are based on implicit observations of users' behaviors. Table I compares their differences.

TABLE 1. RECOMMENDER SYSTEM COMPARISON

\begin{tabular}{|l|l|c|}
\hline \multicolumn{1}{|c|}{ Item } & \multicolumn{1}{|c|}{ Explicit } & Implicit \\
\cline { 1 - 2 } $\begin{array}{l}\text { Feedback provided by } \\
\text { users }\end{array}$ & $\begin{array}{l}\text { Users provide feedback } \\
\text { directly. Private } \\
\text { information leakage } \\
\text { may occur. }\end{array}$ & None \\
\cline { 1 - 1 } Data accuracy & High & Low \\
\cline { 1 - 2 } Gather user information & Low & High \\
\cline { 1 - 2 } Computation Load & & \\
\hline
\end{tabular}

Figure 1 displays three most popular recommendation approaches: collaborative filtering, content-based filtering and hybrid recommender. 
First introduced by Goldberg et al. [2] in 1992, collaborative filtering was presented in their email filtering system, Tapestry. According to the known preferences of a group of users, the system could help other users perform filtering and make recommendations.

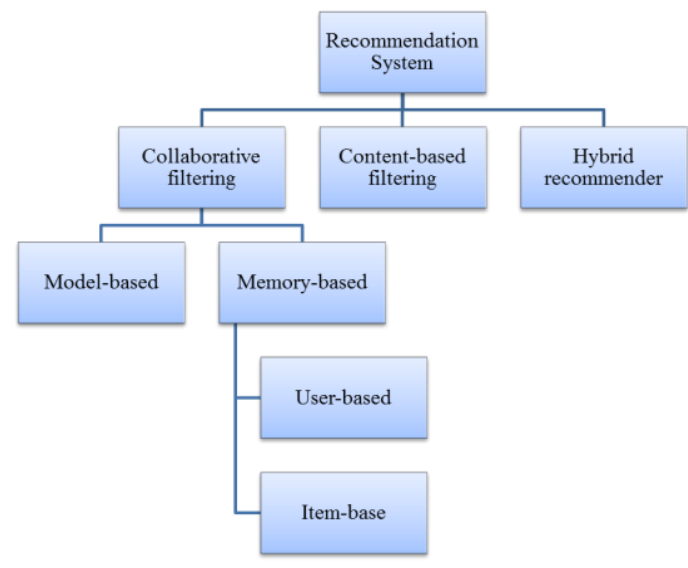

Figure 1. Recommendation approaches

Collaborative filtering approach collects user ratings on items to predict user preferences. Based on the opinions of other users who share similar interests, the approach filters items and makes recommendations. Using the collaborative filtering approach, people can help each other to perform filtering. In e-commerce recommender systems, collaborative filtering that make recommendations according to the shopping experiences of similar users is the most important and widely used approach.

Collaborative filtering approaches, as listed in Table II, can be divided into two categories: model-based and memorybased.

TABLE 2. TYPES OF COLLABORATIVE FILTERING

\begin{tabular}{|c|c|c|c|}
\hline Category & Subtype & Description & Example \\
\hline $\begin{array}{l}\text { Model- } \\
\text { based }\end{array}$ & & $\begin{array}{l}\text { Train a model based on the } \\
\text { known data to make } \\
\text { predictions or and } \\
\text { recommendations. }\end{array}$ & $\begin{array}{l}\text { Bayesian } \\
\text { model }\end{array}$ \\
\hline \multirow[t]{2}{*}{$\begin{array}{l}\text { Memory- } \\
\text { based }\end{array}$} & $\begin{array}{l}\text { User- } \\
\text { based }\end{array}$ & $\begin{array}{l}\text { Use the statistical method } \\
\text { to find a group of users with } \\
\text { similar interests. The } \\
\text { processing time will } \\
\text { increase with the increasing } \\
\text { number of users. }\end{array}$ & \multirow[t]{2}{*}{$\begin{array}{l}\text { Nearest } \\
\text { Neighbors } \\
\text { Search, } \\
\text { NNS }\end{array}$} \\
\hline & $\begin{array}{l}\text { Item- } \\
\text { based }\end{array}$ & $\begin{array}{l}\text { Compute the similarities } \\
\text { between items, instead of } \\
\text { users. }\end{array}$ & \\
\hline
\end{tabular}

Content-based filtering approach makes recommendations according to history of user activities, rather than relations between users and items. For this reason, new items may be excluded from the recommendation list. This approach can work based on any user-item historical interactions. Though simple, it can never work when there is no historical data.

Hybrid recommender approach that uses advantages of two or more recommender methods enhances its computational structure to improve not only the recommender systems but also the recommendation accuracy. The hybrid approach that combines collaborative filtering and contentbased filtering together is the most common combination. The advantages and disadvantages of the three recommendation approaches are given in Table III.

TABLE 3. COMPARISON OF THREE RECOMMENDATION APPROACHES

\begin{tabular}{|c|c|c|}
\hline $\begin{array}{c}\text { Recommendation } \\
\text { Technique }\end{array}$ & Advantages & Disadvantages \\
\hline $\begin{array}{l}\text { Content-based } \\
\text { filtering }\end{array}$ & $\begin{array}{l}\text { Explainable } \\
\text { recommendations. }\end{array}$ & $\begin{array}{l}\text { 1. New user problem. } \\
\text { 2. Depends on historical } \\
\text { data. Unable to make } \\
\text { good } \\
\text { recommendations } \\
\text { when there is no } \\
\text { sufficient historical } \\
\text { data. }\end{array}$ \\
\hline $\begin{array}{l}\text { Collaborative } \\
\text { filtering }\end{array}$ & $\begin{array}{l}\text { 1. Customized } \\
\text { recommendations } \\
\text { with the } \\
\text { increasing number } \\
\text { of users and items. } \\
\text { 2. Higher } \\
\text { recommendation } \\
\text { accuracy over } \\
\text { time. }\end{array}$ & $\begin{array}{l}\text { 1. New user problem. } \\
\text { 2. New item problem. } \\
\text { 3. Depends on historical } \\
\text { data. Unable to make } \\
\text { good } \\
\text { recommendations } \\
\text { when there is no } \\
\text { sufficient historical } \\
\text { data. }\end{array}$ \\
\hline $\begin{array}{l}\text { Hybrid } \\
\text { recommender }\end{array}$ & $\begin{array}{l}\text { Solve new user and } \\
\text { new item problem. }\end{array}$ & $\begin{array}{l}\text { More complex } \\
\text { computing. }\end{array}$ \\
\hline
\end{tabular}

\section{B. Brief Intro to Web 2.0}

Instead of being identified by a software standard, Web 2.0, which is considered as a platform, refers to special usercentered web applications that enable information sharing and collaborative works on the Internet. Typical Web 2.0 applications include RSS, blogs, Wiki, social networking websites and so on.

While Web 1.0 was a one-way information provider with little interaction between the user and the website, Web 2.0 is user-oriented.

TABLE 4. DIFFERENCES BETWEEN WEB 1.0 AND WEB 2.0

\begin{tabular}{|c|c|c|}
\hline Web 1.0 & \multirow{14}{*}{$\rightarrow$} & Web 2.0 \\
\hline DoubleClick & & Google AdSense \\
\hline Ofoto & & Flickr \\
\hline Akamai & & BitTorrent \\
\hline mp3.com & & Napster \\
\hline Britannica Online & & Wikipedia \\
\hline personal websites & & blogging \\
\hline evite & & $\begin{array}{l}\text { upcoming.org and } \\
\text { EVDB }\end{array}$ \\
\hline $\begin{array}{l}\text { domain name } \\
\text { speculation }\end{array}$ & & $\begin{array}{l}\text { search engine } \\
\text { optimization }\end{array}$ \\
\hline page views & & cost per click \\
\hline screen scraping & & web services \\
\hline publishing & & participation \\
\hline $\begin{array}{l}\text { content management } \\
\text { systems }\end{array}$ & & wikis \\
\hline $\begin{array}{l}\text { directories } \\
(\text { taxonomy) }\end{array}$ & & $\begin{array}{c}\text { tagging } \\
\text { ("folksonomy") }\end{array}$ \\
\hline
\end{tabular}

Source: O'Reilly（2005）

$\underline{\text { RSS }}$ (Really Simple Syndication):

RSS is a format for delivering regularly changing web content like blogs, news headlines and information exchange. To subscribe to RSS feeds, users or applications are able to receive most recent updates.

Blog:

Blogs, one of web 2.0 applications, allow users to have their own blogs or websites, become content sources, and 
transform into self-media. Each blog may comprise information, including text, pictures, graphics, audio or video. Recent famous blog service providers in Taiwan include the "Wretch" blog and the "PIXNET" blog.

\section{Wiki:}

Wiki is an open-source, collaborative system in which anyone can publish, edit and share. All types of users can contribute knowledge and peers can edit and help improve it. https://en.wikipedia.org/wiki/Wiki

\section{Social Network:}

Social networks that rely on human-to-human interactions have been a new form of communication, like Facebook, for example. Social network, the basis of our proposed recommender system, will be further defined in the following Section 2.3 .

\section{Social Network}

A social network is comprised of a group of people who share similar personal interests, and can be a way to stay connected or befriend with others. Based on the idea, social networking sites are online platforms that people use to build social networks. Using the Internet, users can interact and share information with each other in real-time without faceto-face communication. In this paper, the social networking websites are used for simulation because each has a great number of users and massive amount of personal data.

Take Facebook as an example. It recommends new friends to users or help reconnect with long-lost friends. Games that users can play on Facebook, like Happy Farm, are able to bring families and friends together and strengthen relationships.

TABlE 5. Advantages And Disadvantages of Social Media

\begin{tabular}{|l|l|}
\hline Advantages & \begin{tabular}{l}
\multicolumn{1}{c|}{ Description } \\
Know more new friends quickly and easily. Able to \\
see friends' status updates in real-time.
\end{tabular} \\
\hline Disadvantages & $\begin{array}{l}\text { Information leakage may happen. Lack of identity } \\
\text { authentication. }\end{array}$ \\
\hline
\end{tabular}

Facebook: In addition to text messages, Facebook users are able to send information to others such as images, photos, pictures and voice messages. Also, Facebook users can add others as friends, connect with them, and receive automatic notifications when friends edit personal information or post status updates.

EdgeRank is the algorithm that Facebook originally used to decide which posts to show first in each user's News Feed. Boring stories are hidden by the algorithm. "So, if your story doesn't score well, no one will see it."

Facebook, at the 2010 F8 Conference, revealed that they use three metrics to calculate EdgeRank:

$$
\sum_{\text {edges } e} u_{e} w_{e} d_{e}
$$

- $\quad u_{e}$ (Affinity Score): How "connected" is a particular user to the edge?

- $\quad w_{e}$ (Edge Weight): What actions were taken by the user on the content?
- $\quad d_{e}$ (Time Decay): How old is the post?

In 2014, Facebook CEO Mark Zuckerberg declared in a press conference that "our goal is to build the perfect personalized newspaper for every person in the world." This newspaper would "show you the stuff that's going to be most interesting to you",

In 2015, Facebook made adjustments to its News Feed algorithm and decided what to prioritize according to the equation: News Feed Visibility $=I \times P \times C \times T \times R$.

- $\quad \mathrm{I}($ Interest $)=$ Interest of the user in the creator.

- $\quad \mathrm{P}($ Post $)=$ The post's performance amongst other users

- $\mathrm{C}($ Creator $)=$ Performance of past posts by the content creator amongst other users.

- $\quad \mathrm{T}$ (Type)=Type of post (status, photo, link) user prefers - $\mathrm{R}($ Recency)= How new the post is.

Facebook, in January 2018, took another move: prioritizing the posts from users' friends and family, and deprioritizing content from businesses, brands, and media.

Yelp:

Yelp was initially an email-based system that users could email their friends with recommendations for restaurants. However, friends might receive so many emails. Later, Yelp added a review system that business owners cannot edit or remove the content on their business pages. To encourage users to write reviews, the company built the Yelp Elite Squad to recognize people who are active in the Yelp community and role models on and off the Yelp site. The Yelp Elite members are invited to local events and meet-ups, inspiring others to contribute their own opinions. Most review sites focus on one single product or service, like hotels or restaurants, and have no functions of social networking. However, Yelp has both.

Yelp has three major functions: (1) Check-In: This function is synchronized with Facebook so that users and their friends are able to see the check-in locations. The number of check-ins is a ranking factor on Yelp; (2) Tips: It is a way to divide long reviews and short ones; (3) Compliment: Users can send a compliment about a review or to a reviewer.

\section{METHODS}

According to the intimacy and friendship on Facebook, this paper uses the indirect relations on Yelp as the sources of data to deal with cold-start problem [6][7].

\section{A. Problem Statement}

People may search across the Internet for reviews for a shop, a location or a product. However, once the search is narrowed down to a particular range, users need to check the reviews one by one, which is an enormously time-consuming process. Users are unable to find what they need quickly.

Generally speaking, most people favor the reviews written by their friends or coworkers, rather than those by strangers.

A cold-start problem means that the recommender system cannot make recommendations for a new user with no history. For example, without enough user history, Facebook would use friends with similar interests to alleviate the cold-start problem. But, if the information is little, the system is still unable to make recommendations[8][9][10]. 
To cope with the above-mentioned problems, we use Yelp check-ins and reviews to determine the relationships between users. Although this is not a novel method, we can find a user's interests and the interest similarities with his/her friends (See Figure 2 and 3). Moreover, different from other systems, we use the sentinel user selection [3] (See Figure 4) as the basis of the recommender system.

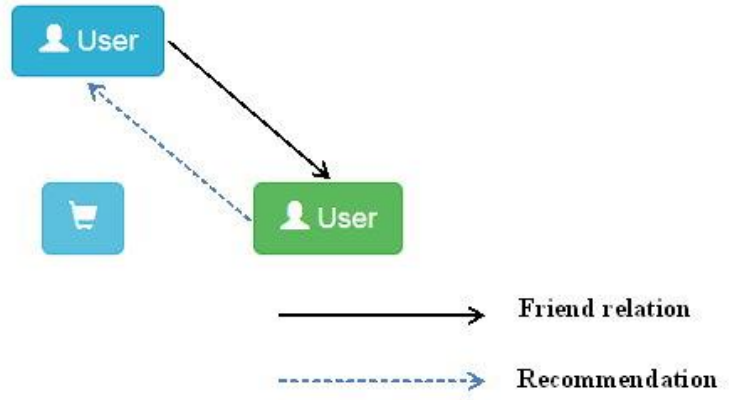

Figure 2. Direct Relation
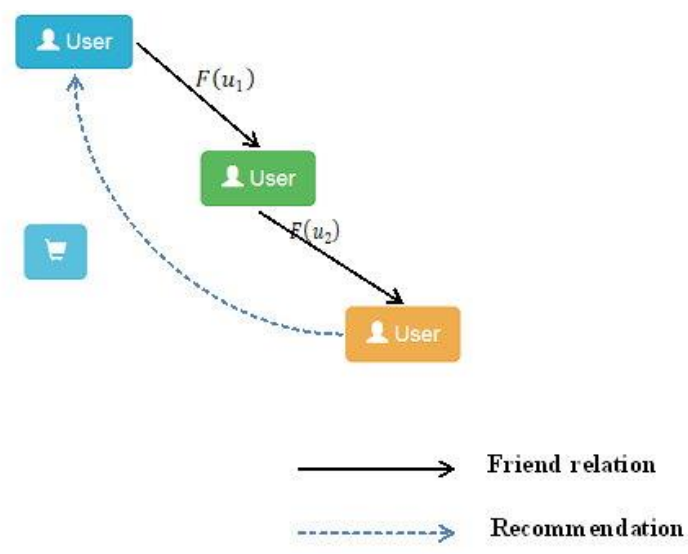

Figure 3. Indirect Relation

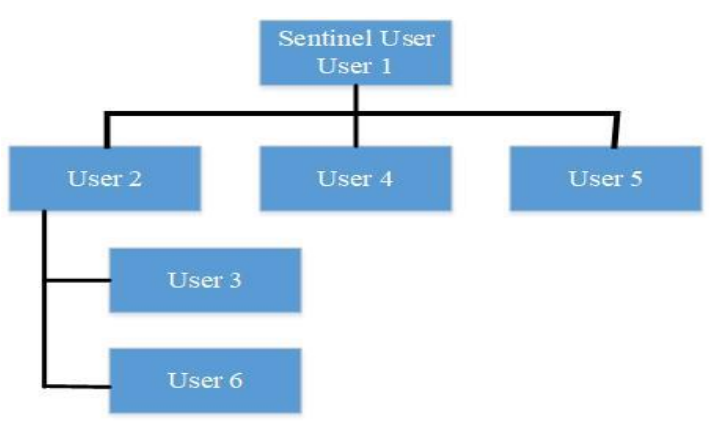

Figure 4. Sentinel User on Top Layer

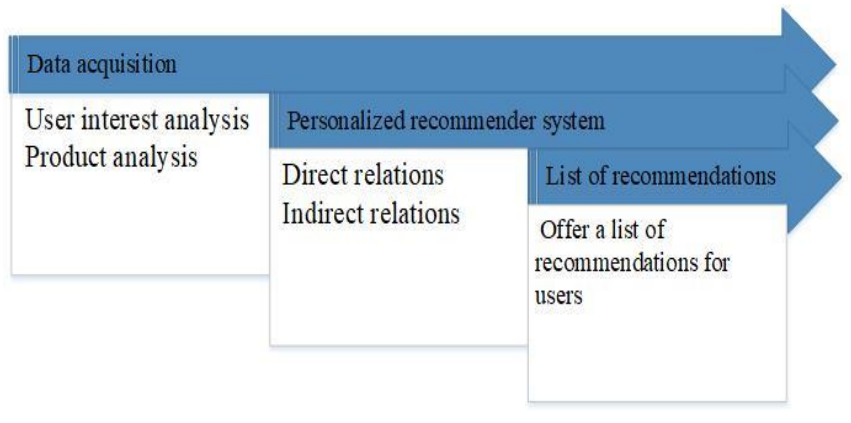

Figure 5. System Framework

\section{B. System Framework}

The system framework consists of three parts: 1. data acquisition, including user interest analysis and product analysis; 2. personalized recommender system, including direct and indirect relations; and 3. list of recommendations.

\section{Procedures}

Our study includes the following steps: 1) Gather user data and user review, 2) Select the business category (Select Food), 3) Select the food types (5 kinds of cuisines), 4) Test the recommendation data, and 5) Analyze the recommendation data.

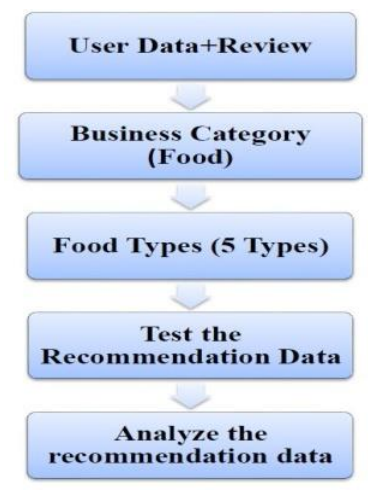

Figure 6. Flowchart

\section{ANALYSIS}

The simulation is based on the crowd-sourced reviews retrieved from the Yelp Dataset. Link: https://www.yelp.com/dataset/

\section{A. Simulation Design}

Yelp collects reviews for not only foods but also businesses. Currently, there are 1,293 kinds of businesses in total based o the Yelp Dataset. Restaurants in the "Food" category, which occupies most of the reviews, will be the focus of our simulation.

\section{$\underline{\text { Steps }}$}

1. Classify the restaurant categories and retrieve data of 13,273 restaurants of the top 5 food types: American (traditional), Italian, Chinese, American (new) and Mexican.

2. Load reviews. Keep only one review written by the same user for the restaurant on the same day.

3. Remove those reviews that are not categorized as useful, interesting, or cool.

4. Get the interest value $I_{u}(c)$

- With user corresponding data,

$$
\mathrm{I}_{\mathrm{u}}(\mathrm{c})=\frac{n_{c}}{\sum_{\mathrm{i}=1}^{j} \mathrm{n}_{\mathrm{i}}}, 1 \leq i \leq j
$$

- Without user corresponding data,

$$
\mathrm{I}_{\mathrm{u}}(\mathrm{c})=\frac{\sum_{\mathrm{i}=1}^{\mathrm{n}} \mathrm{F}_{\mathrm{i}}(\mathrm{u}) \times \mathrm{I}_{\mathrm{fi}}(\mathrm{c})}{\sum_{\mathrm{i}=1}^{\mathrm{n}} \mathrm{F}_{\mathrm{i}}(\mathrm{u})}, i \leq n
$$

5. Calculate the recommendation ratio to users.

$$
\mathrm{R}(c)=\frac{I_{u}(c)}{\sum_{k=1}^{j} I(k)}, 1 \leq \mathrm{c} \leq \mathrm{j}
$$

6. Load reviews. Keep only one review written by the same 
user for the restaurant on the same day.

7. Remove those reviews that are not categorized as useful, interesting, or cool.

8. Get the interest value $\mathrm{I}_{\mathrm{u}}(\mathrm{c})$

1. With user corresponding data,

$$
\mathrm{I}_{\mathrm{u}}(\mathrm{c})=\frac{n_{c}}{\sum_{\mathrm{i}=1}^{j} \mathrm{n}_{\mathrm{i}}}, 1 \leq i \leq j
$$

2. Without user corresponding data,

$$
\mathrm{I}_{\mathrm{u}}(\mathrm{c})=\frac{\sum_{\mathrm{i}=1}^{\mathrm{n}} \mathrm{F}_{\mathrm{i}}(\mathrm{u}) \times \mathrm{I}_{\mathrm{fi}}(\mathrm{c})}{\sum_{\mathrm{i}=1}^{\mathrm{n}} \mathrm{F}_{\mathrm{i}}(\mathrm{u})}, i \leq n
$$

9. Calculate the recommendation ratio to users.

$$
\mathrm{R}(c)=\frac{I_{u}(c)}{\sum_{k=1}^{j} I(k)}, 1 \leq \mathrm{c} \leq \mathrm{j}
$$

\section{Test Steps}

To compute the popularity weight, all parameters in each category are weighted so that users can find the item with the top $\mathrm{R}(\mathrm{c})$.

There are two weighting variables: (1) Popularity of Place, $P(P)$ : Users' desired restaurants are usually hot attractions or iconic spots, (2) Places that have been visited by friends, $F(P)$ : Users are also interested in the places which friends have already visited. Other parameters include:

- $W(p)$ : Popularity weight.

- $\alpha$ : Weight value of popularity.

- $P(p)$ : Popularity of Place.

- $\beta$ : Weight value of friends' reviews.

- $F(p)$ : Places that have been visited by friends.

1. Calculate $\mathrm{P}(p)$ and $\mathrm{F}(p)$

$$
\begin{gathered}
\mathrm{P}(p)=\frac{n_{c h, p}}{\max \left(n_{c h, p}\right)}+\frac{n_{l i, p}}{\max \left(n_{l i, p}\right)} \\
F(p)=\frac{n_{c}}{n_{s}}
\end{gathered}
$$

2. Sentinel user's interest in a specific item, $A(p)$

$$
A(p)=\frac{\sum_{i=1}^{n_{p}} S C_{i}}{n_{p}}
$$

3. Calculate the weight value, $W^{\prime}(p)$

$$
\mathrm{W}^{\prime}(p)=W(p)+A(p)
$$

4. Calculate the new interest value $I_{u}{ }^{\prime}(c)$

$$
I_{u}{ }^{\prime}(c)=I_{u}(c)+\alpha_{c} A(p)
$$

5. Regulate $\mathrm{R}(c)$ with the new interest value $I_{u}{ }^{\prime}(c)$

$$
\mathrm{R}(c)=\frac{I_{u}^{\prime}(c)}{\sum_{k=1}^{j} I(k)}, 1 \leq \mathrm{c} \leq \mathrm{j}
$$

\section{Evaluation Metrics}

Mean Reciprocal Rank, MRR: MRR is a measure of the accuracy and average rank. The following equation shows that MRR is the average of the reciprocal ranks of results for a sample of queries $n$ :

$$
\mathrm{MRR}=\frac{1}{n} \sum_{i=1}^{n} s e q_{i}
$$

$s e q_{i}$ refers to the rank position of the first relevant document for the ith query. According to the predicted probability, the top $\mathrm{k}$ items are compared. When an item is relevant and predicted correctly, a score is assigned. The earlier the item appears, the higher the score is, i.e. $R R=1$. If there is no correct item, $R R=0$. The mean value of $n$ experiments is MRR.

\section{B. Simulation Data and Results}

- $\quad$ Scenario 1: Reviews submitted to Yelp from Jan. 1, 2016 to Dec. 31, 2016 were taken for simulation. Among those, we retrieved 20 reviews written by users who also wrote reviews between Jan. 1, 2017 and Dec. 22, 2017 to estimate accurate recommendations for new items.

- $\quad$ Scenario 2: 20 Reviews submitted to Yelp from Jan. 1, 2017 to Dec. 22, 2017 were taken for simulation to estimate accurate recommendations for new items.

\section{RESUlTS}

\section{Scenario 1:}

TABLE 6. MRR based on user history only $=57 \%$

\begin{tabular}{|c|c|c|c|}
\hline User & MRR & User & MRR \\
\hline 1 & $1 / 4$ & 11 & 1 \\
\hline 2 & $1 / 2$ & 12 & 1 \\
\hline 3 & $1 / 2$ & 13 & $1 / 3$ \\
\hline 4 & 1 & 14 & $1 / 3$ \\
\hline 5 & 1 & 15 & $1 / 2$ \\
\hline 6 & $1 / 5$ & 16 & $1 / 3$ \\
\hline 7 & $1 / 2$ & 17 & 1 \\
\hline 8 & $1 / 2$ & 18 & $1 / 2$ \\
\hline 9 & $1 / 4$ & 19 & 1 \\
\hline 10 & $1 / 2$ & 20 & $1 / 5$ \\
\hline
\end{tabular}

TABLE 7. MRR based on friend recommendation $=57.25 \%$

\begin{tabular}{|c|c|c|c|}
\hline User & MRR & User & MRR \\
\hline 1 & $1 / 3$ & 11 & 1 \\
\hline 2 & $1 / 2$ & 12 & 1 \\
\hline 3 & $1 / 2$ & 13 & $1 / 3$ \\
\hline 4 & 1 & 14 & $1 / 3$ \\
\hline 5 & 1 & 15 & $1 / 2$ \\
\hline 6 & $1 / 5$ & 16 & $1 / 3$ \\
\hline 7 & $1 / 3$ & 17 & 1 \\
\hline 8 & $1 / 2$ & 18 & $1 / 2$ \\
\hline 9 & $1 / 4$ & 19 & 1 \\
\hline 10 & $1 / 2$ & 20 & $1 / 3$ \\
\hline
\end{tabular}

The table showed that the recommendation results based on friends' reviews were better.

TABLE 8. MRR based on friend recommendation and $\mathrm{A}(\mathrm{P})=58.5 \%$

\begin{tabular}{|c|c|c|c|}
\hline User & MRR & User & MRR \\
\hline 1 & $1 / 3$ & 11 & 1 \\
\hline 2 & $1 / 2$ & 12 & 1 \\
\hline 3 & $1 / 2$ & 13 & $1 / 3$ \\
\hline 4 & 1 & 14 & $1 / 2$ \\
\hline 5 & 1 & 15 & $1 / 2$ \\
\hline 6 & $1 / 5$ & 16 & $1 / 2$ \\
\hline 7 & $1 / 3$ & 17 & 1 \\
\hline 8 & $1 / 2$ & 18 & $1 / 2$ \\
\hline 9 & $1 / 4$ & 19 & 1 \\
\hline 10 & 1 & 20 & $1 / 4$ \\
\hline
\end{tabular}

The table proved that the addition of sentinel friend improved recommendation accuracy. 


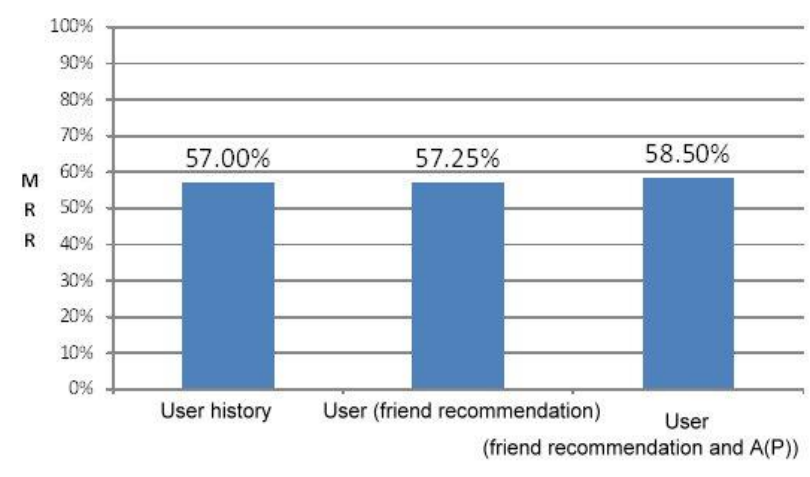

Figure 7. MRR: User history, User (friend recommendation), and User (friend recommendation and $\mathrm{A}(\mathrm{P})$ )

TABLE 9. MRR based on $\mathrm{A}(\mathrm{P})$ and $\mathrm{P}(\mathrm{P})$ review category $=56.8333 \%$

\begin{tabular}{|c|c|c|c|}
\hline User & MRR & User & MRR \\
\hline 1 & $1 / 3$ & 11 & 1 \\
\hline 2 & $1 / 2$ & 12 & 1 \\
\hline 3 & $1 / 2$ & 13 & $1 / 3$ \\
\hline 4 & $1 / 2$ & 14 & $1 / 2$ \\
\hline 5 & 1 & 15 & $1 / 2$ \\
\hline 6 & $1 / 5$ & 16 & $1 / 2$ \\
\hline 7 & $1 / 3$ & 17 & 1 \\
\hline 8 & $1 / 3$ & 18 & $1 / 3$ \\
\hline 9 & $1 / 4$ & 19 & 1 \\
\hline 10 & 1 & 20 & $1 / 4$ \\
\hline
\end{tabular}

TABLE 10. MRR based on $\mathrm{A}(\mathrm{P})$ and $\mathrm{F}(\mathrm{P})$ review category $=61 \%$

\begin{tabular}{|c|c|c|c|}
\hline User & MRR & User & MRR \\
\hline 1 & $1 / 3$ & 11 & 1 \\
\hline 2 & $1 / 2$ & 12 & 1 \\
\hline 3 & $1 / 2$ & 13 & $1 / 3$ \\
\hline 4 & 1 & 14 & $1 / 3$ \\
\hline 5 & 1 & 15 & $1 / 2$ \\
\hline 6 & $1 / 5$ & 16 & $1 / 2$ \\
\hline 7 & $1 / 3$ & 17 & 1 \\
\hline 8 & $1 / 2$ & 18 & $1 / 2$ \\
\hline 9 & $1 / 4$ & 19 & 1 \\
\hline 10 & 1 & 20 & $1 / 4$ \\
\hline
\end{tabular}

The table proved that the recommendation accuracy based on $\mathrm{F}(\mathrm{P})$ was better than that based on $\mathrm{P}(\mathrm{P})$.

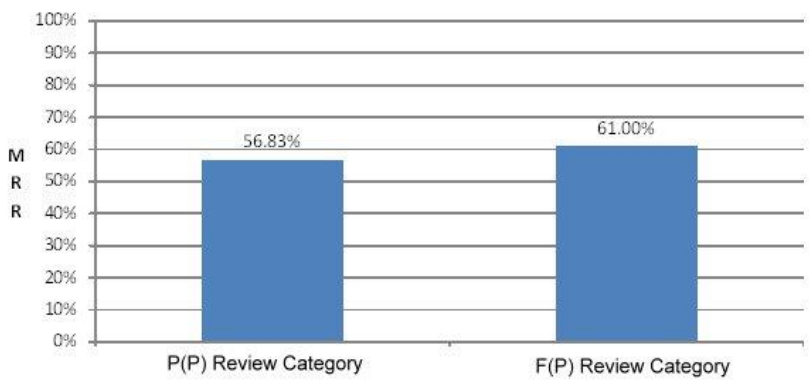

Figure 8. (New Item based on $\mathrm{A}(\mathrm{P})$ ) MRR comparison between $\mathrm{P}(\mathrm{P})$ and $\mathrm{F}(\mathrm{P})$ review category

Scenario 2:

Classical probability is the statistical concept that assumes that all outcomes in the experiment are likely to occur equally. The probability of an event is equal to the ratio of the number of favorable outcomes to the total number of possible outcomes for the experiment.
Probability of an event $=\frac{\text { Number of favorable outcomes }}{\text { Total number of possible outcomes }}$

Scenario 2 focuses on new users who did not submit reviews in 2016. Therefore, the classical probability for the experiment is $1 / 5=20 \%$

TABLE 11. MRR based on friend recommendation $=34.25 \%$

\begin{tabular}{|c|c|c|c|}
\hline User & MRR & User & MRR \\
\hline 1 & $1 / 3$ & 11 & $1 / 3$ \\
\hline 2 & 1 & 12 & $1 / 5$ \\
\hline 3 & $1 / 2$ & 13 & $1 / 3$ \\
\hline 4 & $1 / 5$ & 14 & $1 / 4$ \\
\hline 5 & $1 / 3$ & 15 & $1 / 3$ \\
\hline 6 & $1 / 2$ & 16 & $1 / 4$ \\
\hline 7 & $1 / 3$ & 17 & $1 / 4$ \\
\hline 8 & $1 / 4$ & 18 & $1 / 5$ \\
\hline 9 & $1 / 3$ & 19 & $1 / 3$ \\
\hline 10 & $1 / 3$ & 20 & $1 / 4$ \\
\hline
\end{tabular}

The table proved that the recommendation results based on friends' reviews were better.

TABLE 12. MRR based on friend recommendation and $\mathrm{A}(\mathrm{P})=34.25 \%$

\begin{tabular}{|c|c|c|c|}
\hline User & MRR & User & MRR \\
\hline 1 & $1 / 3$ & 11 & $1 / 3$ \\
\hline 2 & 1 & 12 & $1 / 5$ \\
\hline 3 & $1 / 2$ & 13 & $1 / 3$ \\
\hline 4 & $1 / 5$ & 14 & $1 / 4$ \\
\hline 5 & $1 / 3$ & 15 & $1 / 3$ \\
\hline 6 & $1 / 2$ & 16 & $1 / 4$ \\
\hline 7 & $1 / 3$ & 17 & $1 / 4$ \\
\hline 8 & $1 / 4$ & 18 & $1 / 5$ \\
\hline 9 & $1 / 3$ & 19 & $1 / 3$ \\
\hline 10 & $1 / 3$ & 20 & $1 / 4$ \\
\hline
\end{tabular}

The table revealed that the addition of sentinel friend did not improve the recommendation accuracy.

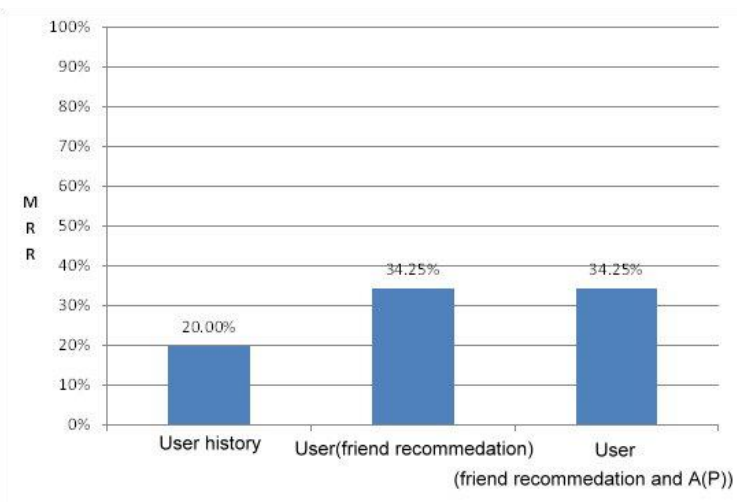

Figure 9. (New User) MRR: User, User (friend recommendation) and User (friend recommendation and $\mathrm{A}(\mathrm{P})$ )

TABLE 13. MRR BASED ON A(P) AND P(P) REVIEW CATEGORY $=$ $31.0833 \%$

\begin{tabular}{|c|c|c|c|}
\hline User & MRR & User & MRR \\
\hline 1 & $1 / 3$ & 11 & $1 / 3$ \\
\hline 2 & $1 / 2$ & 12 & $1 / 5$ \\
\hline 3 & $1 / 4$ & 13 & $1 / 2$ \\
\hline 4 & $1 / 5$ & 14 & $1 / 4$ \\
\hline 5 & $1 / 3$ & 15 & $1 / 3$ \\
\hline 6 & $1 / 2$ & 16 & $1 / 5$ \\
\hline 7 & $1 / 3$ & 17 & $1 / 3$ \\
\hline 8 & $1 / 4$ & 18 & $1 / 5$ \\
\hline 9 & $1 / 3$ & 19 & $1 / 3$ \\
\hline 10 & $1 / 4$ & 20 & $1 / 4$ \\
\hline
\end{tabular}


The table revealed that the outcome based on $\mathrm{A}(\mathrm{P})$ and $\mathrm{P}(\mathrm{P})$ review category was different from the sentinel mechanism.

TABLE 14. MRR BASED ON A(P) AND F(P) REVIEW CATEGORY $=$ $33.8333 \%$

\begin{tabular}{|c|c|c|c|}
\hline User & MRR & User & MRR \\
\hline 1 & $1 / 3$ & 11 & $1 / 3$ \\
\hline 2 & 1 & 12 & $1 / 5$ \\
\hline 3 & $1 / 3$ & 13 & $1 / 3$ \\
\hline 4 & $1 / 5$ & 14 & $1 / 4$ \\
\hline 5 & $1 / 3$ & 15 & $1 / 3$ \\
\hline 6 & $1 / 2$ & 16 & $1 / 4$ \\
\hline 7 & $1 / 3$ & 17 & $1 / 3$ \\
\hline 8 & $1 / 4$ & 18 & $1 / 5$ \\
\hline 9 & $1 / 3$ & 19 & $1 / 3$ \\
\hline 10 & $1 / 3$ & 20 & $1 / 4$ \\
\hline
\end{tabular}

The table revealed that the outcome based on $\mathrm{A}(\mathrm{P})$ and $\mathrm{F}(\mathrm{P})$ review category was different from the sentinel mechanism.

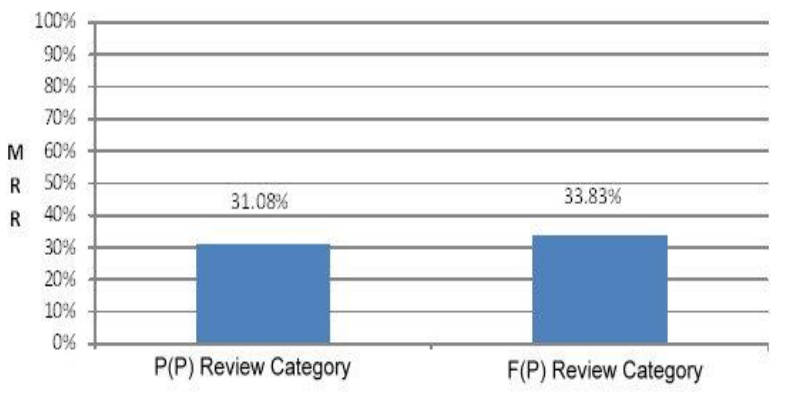

Figure 10. (New User based on $\mathrm{A}(\mathrm{P})$ ) MRR comparison between $\mathrm{P}(\mathrm{P})$ and $\mathrm{F}(\mathrm{P})$ review category

\section{DISCUSSION}

To cope with the cold-start problem, this paper proposes to use the indirect relations in social networks. The system can get data from users' friends and even from their friends' friends to alleviate the new user problem. For the development of new items or new applications, our proposed "indirect relations" can be served as a solution to the problem of coldstart. The simulation reveals that our proposed method together with the sentinel user is able to achieve higher recommendation accuracy than other methods.

\section{ACKNOWLEDGMENT}

This study was supported by the Ministry of Science and Technology, Taiwan, R.O.C., under grant No. MOST 1072221-E-197-007-MY3 and MOST 108-2321-B-197-004.

\section{DECLARATIONS SECTION}

Ethics approval: This paper does not involve animal or human experiments.

Consent to participate: Not applicable.

Availability of data and material: The data used to support the findings of this study are available from the corresponding author upon request.

Competing interests: The authors have declared that no competing interests exist.
Funding: This study was supported by the Ministry of Science and Technology, Taiwan, R.O.C., under grant No. MOST 107-2221-E-197-007-MY3 and MOST 107-2321-B197-004-

Authors' contributions: Tey Fu Jie is responsible for the research process and model design. Tin-Yu Wu is responsible for experimental design. Chiao-Ling Lin is responsible for data analysis. Jiann-Liang Chen is related literature survey.

Acknowledgements: Thanks the Ministry of Science and Technology to supported Funding.

\section{REFERENCES}

[1] F. Abel, E. Herder, G.-J. Houben, N. Henze, and D. Krause, "Crosssystem user modeling and personalization on the socialWeb", User Model. User-Adapt. Interaction, vol. 23, nos. 23, pp. 169209, 2013.

[2] Goldberg D, Nichols D, Oki BM, Terry D, "Using collaborative filtering to weave an information tapestry", Communications of the ACM, pp. 61-70, 1992.

[3] Zhongchen Miao, Junchi Yan, Kai Chen, Xiaokang Yang, Hongyuan Zha, and Wenjun Zhang, "Joint Prediction of Rating and Popularity for Cold-Start Item by Sentinel User Selection”, IEEE Access, vol. 6, pp.8500-8513, Nov. 2016.

[4] K. Kesorn , W. Juraphanthong, A. Salaiwarkul, "Personalized Attraction Recommendation System for Tourists Through Check-In Data”, IEEE Access, vol. 5, pp. 26703-26721, 2017.

[5] Lasitha Uyangoda, Supunmali Ahangama, Tharindu Ranasinghe, "User Profile Feature-Based Approach to Address the Cold Start Problem in Collaborative Filtering for Personalized Movie Recommendation", 2018 Thirteenth International Conference on Digital Information Management (ICDIM),September 2018.

[6] Peter Gaspar, Michal Kompan, Matej Koncal, Maria Bielikova, "Improving the Personalized Recommendation in the Cold-start Scenarios", 2019 IEEE International Conference on Data Science and Advanced Analytics (DSAA), October 2019.

[7] Yaru Jin, Shoubin Dong, Yong Cai, Jinlong Hu, "RACRec: Review Aware Cross-Domain Recommendation for Fully-Cold-Start User", IEEE Access, Vol. 8, pp. 55032-55041, March 2020.

[8] Yichao Zhou, Zhenmin Tang, Lianyong Qi, Xuyun Zhang, Wanchun Dou, Shaohua Wan, "Intelligent Service Recommendation for ColdStart Problems in Edge Computing", IEEE Access, Vol. 7, pp. 4663746645, April 2019.

[9] Yaman Kumar, Agniv Sharma, Abhigyan Khaund, Akash Kumar, Ponnurangam Kumaraguru, Rajiv Ratn Shah, Roger Zimmermann, "IceBreaker: Solving Cold Start Problem for Video Recommendation Engines", 2018 IEEE International Symposium on Multimedia (ISM), December 2018.

[10] Yu Zhu, Jinghao Lin, Shibi He, Beidou Wang, Ziyu Guan, Haifeng Liu, Deng Cai, "Addressing the Item Cold-Start Problem by AttributeDriven Active Learning", EEE Transactions on Knowledge and Data Engineering, Vol. 32, Issue 4, April 2020. 
Figures

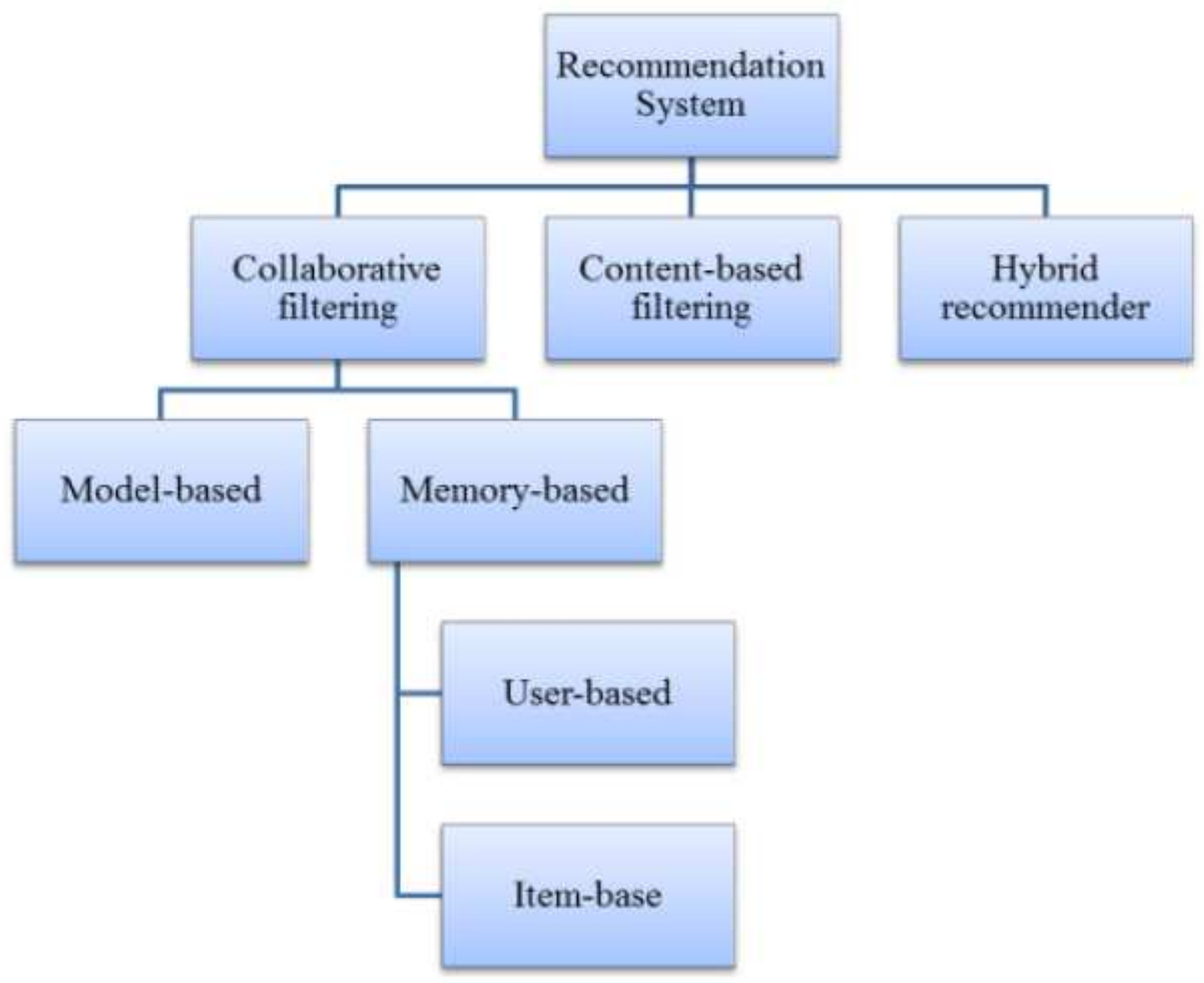

Figure 1

Recommendation approaches 


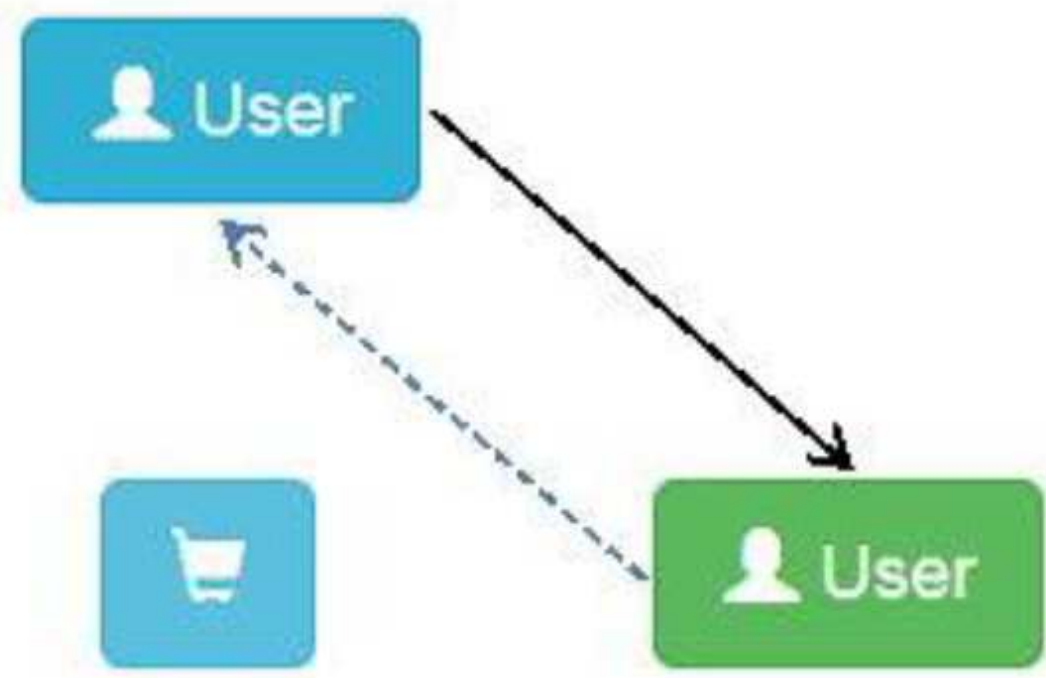

\section{Friend relation}

Recommendation

Figure 2

Direct Relation 

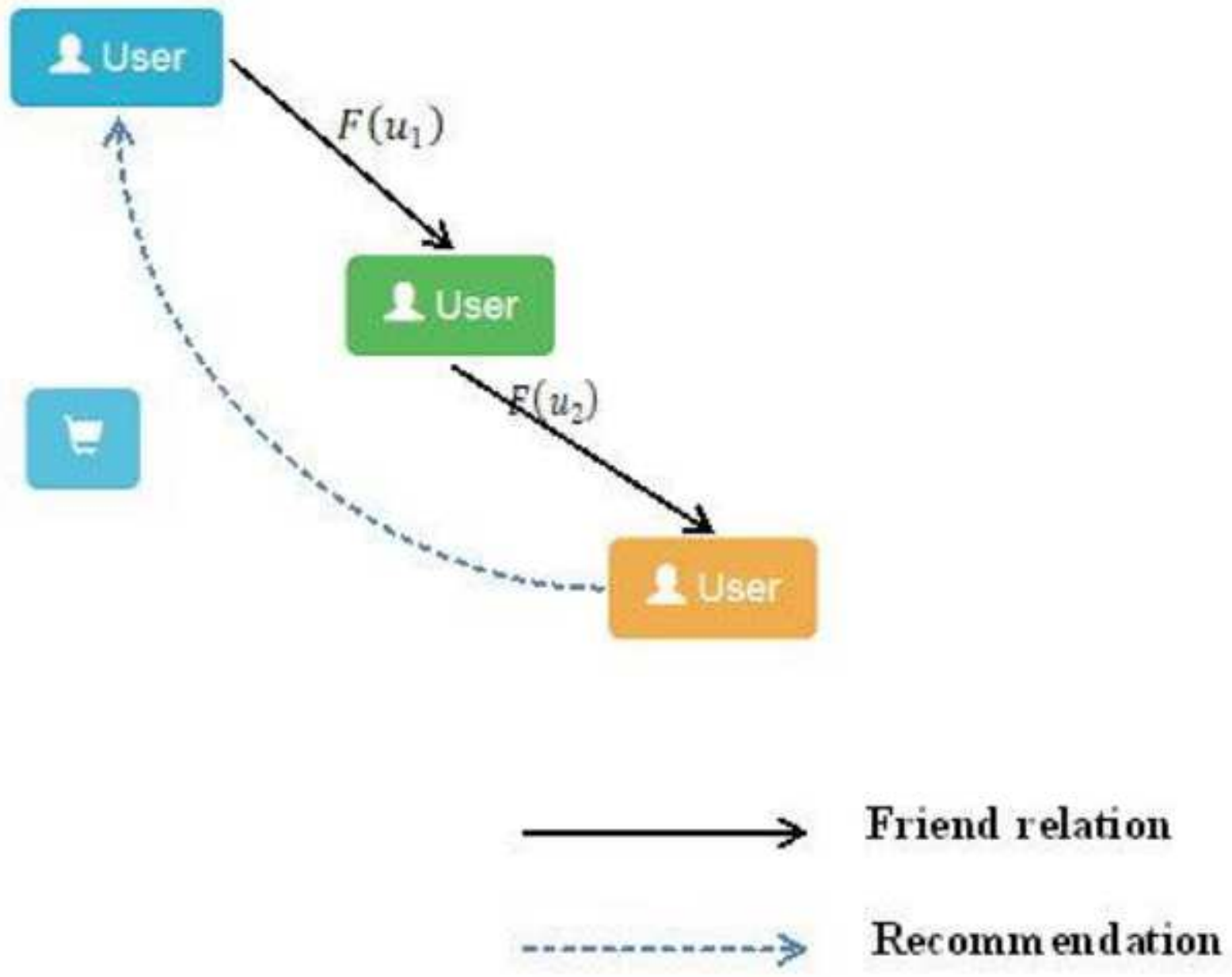

Figure 3

Indirect Relation 


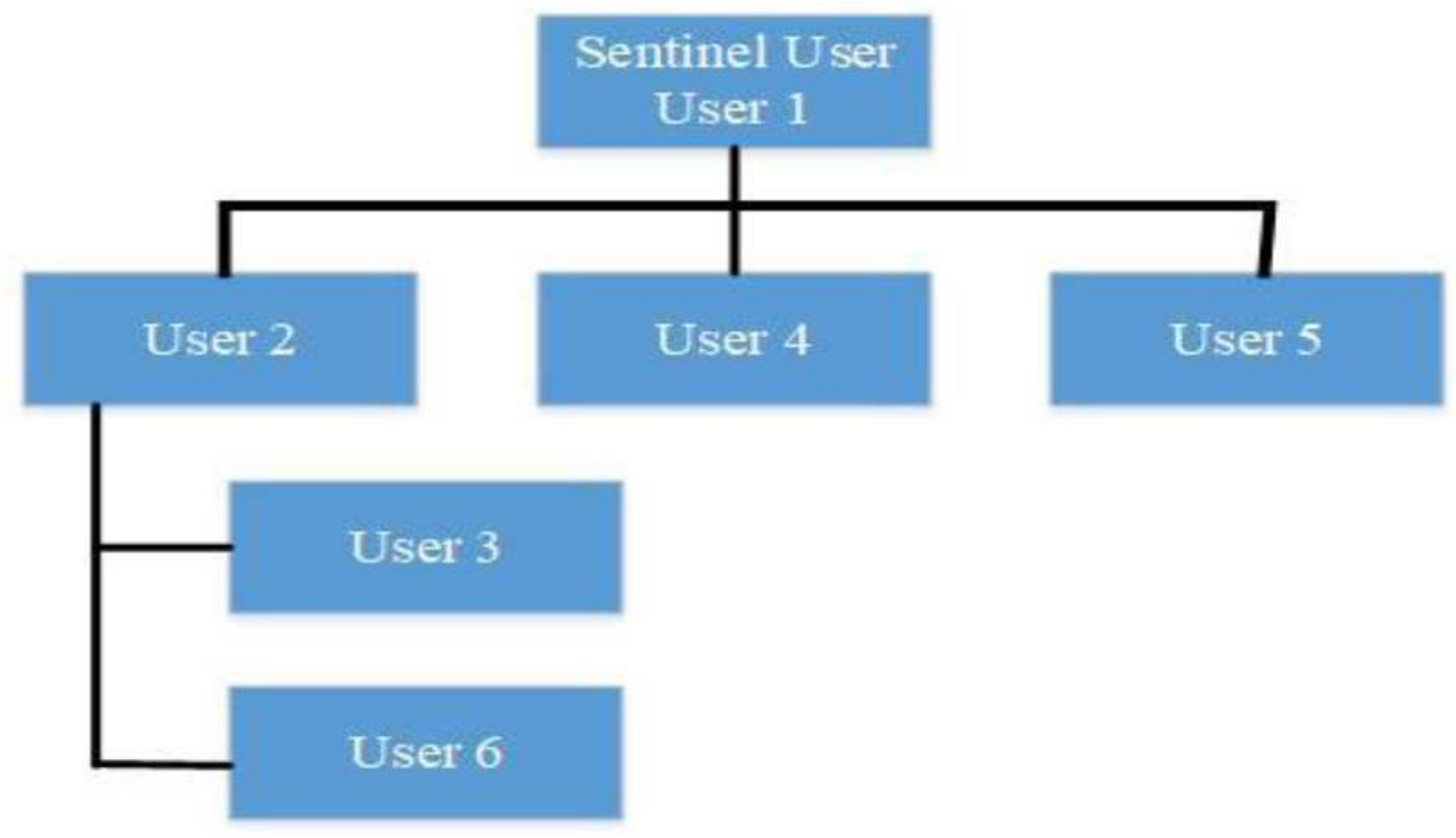

Figure 4

Sentinel User on Top Layer

Data acquisition

User interest analysis Personalized recommender system Product analysis

\section{Direct relations \\ List of recommendations} Indirect relations
Offer a list of recommendations for users

Figure 5 


\section{User Data+Review}

\section{Business Category}

(Food)

Food Types (5 Types)

Test the

Recommendation Data

\section{Analyze the}

recommendation data

Figure 6

Flowchart

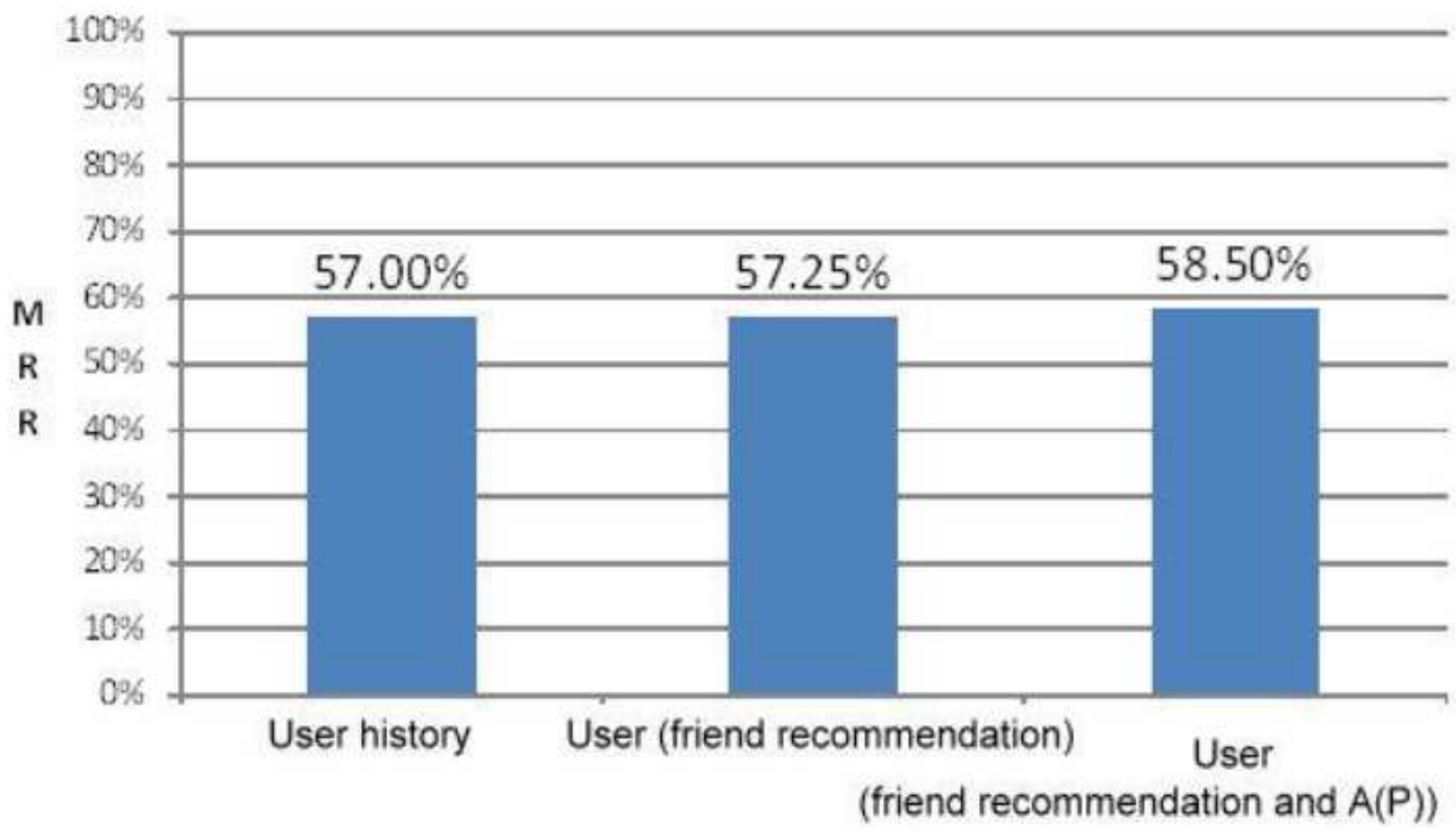


Figure 7

MRR: User history, User (friend recommendation), and User (friend recommendation and $A(P)$ )

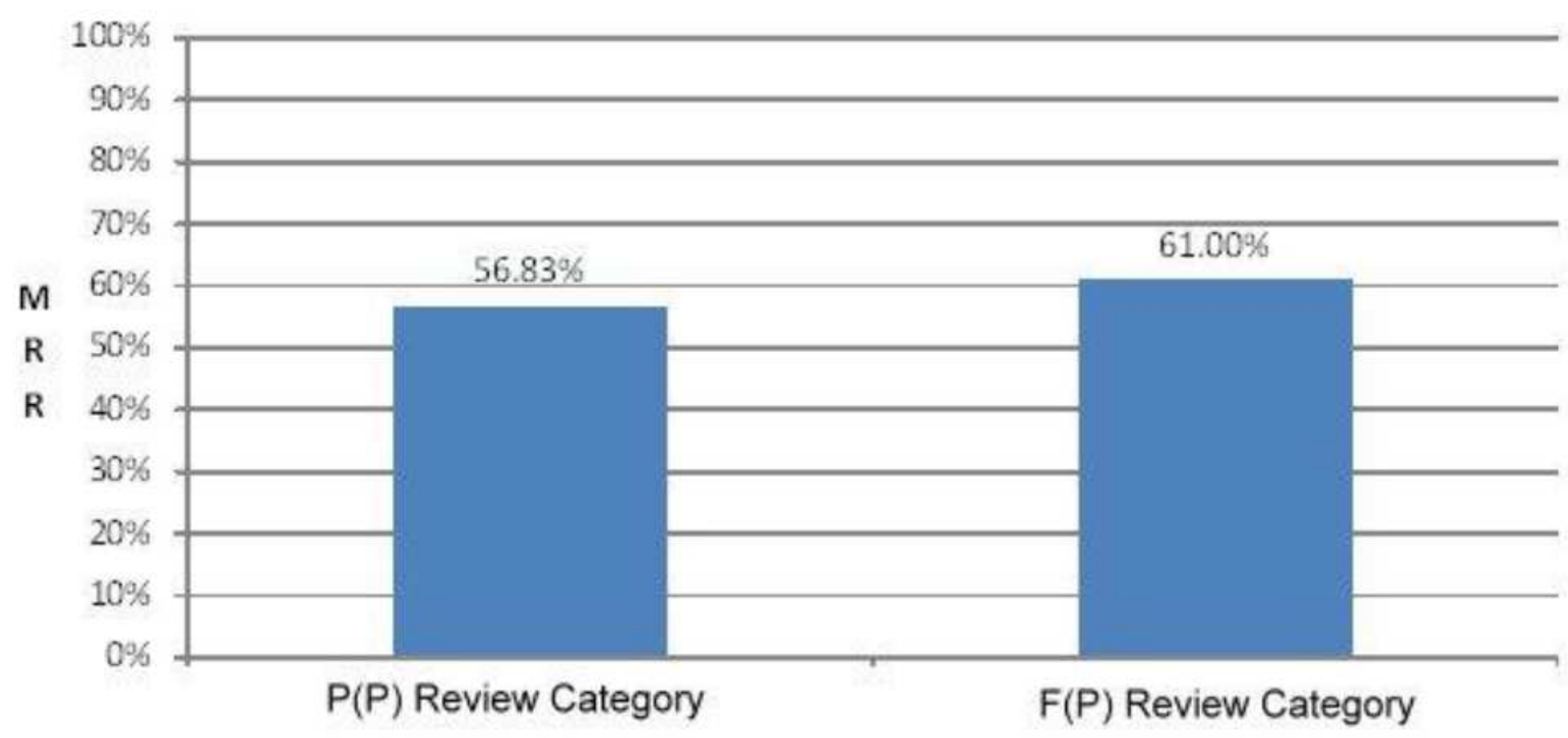

Figure 8

(New Item based on $A(P)$ ) MRR comparison between $P(P)$ and $F(P)$ review category 


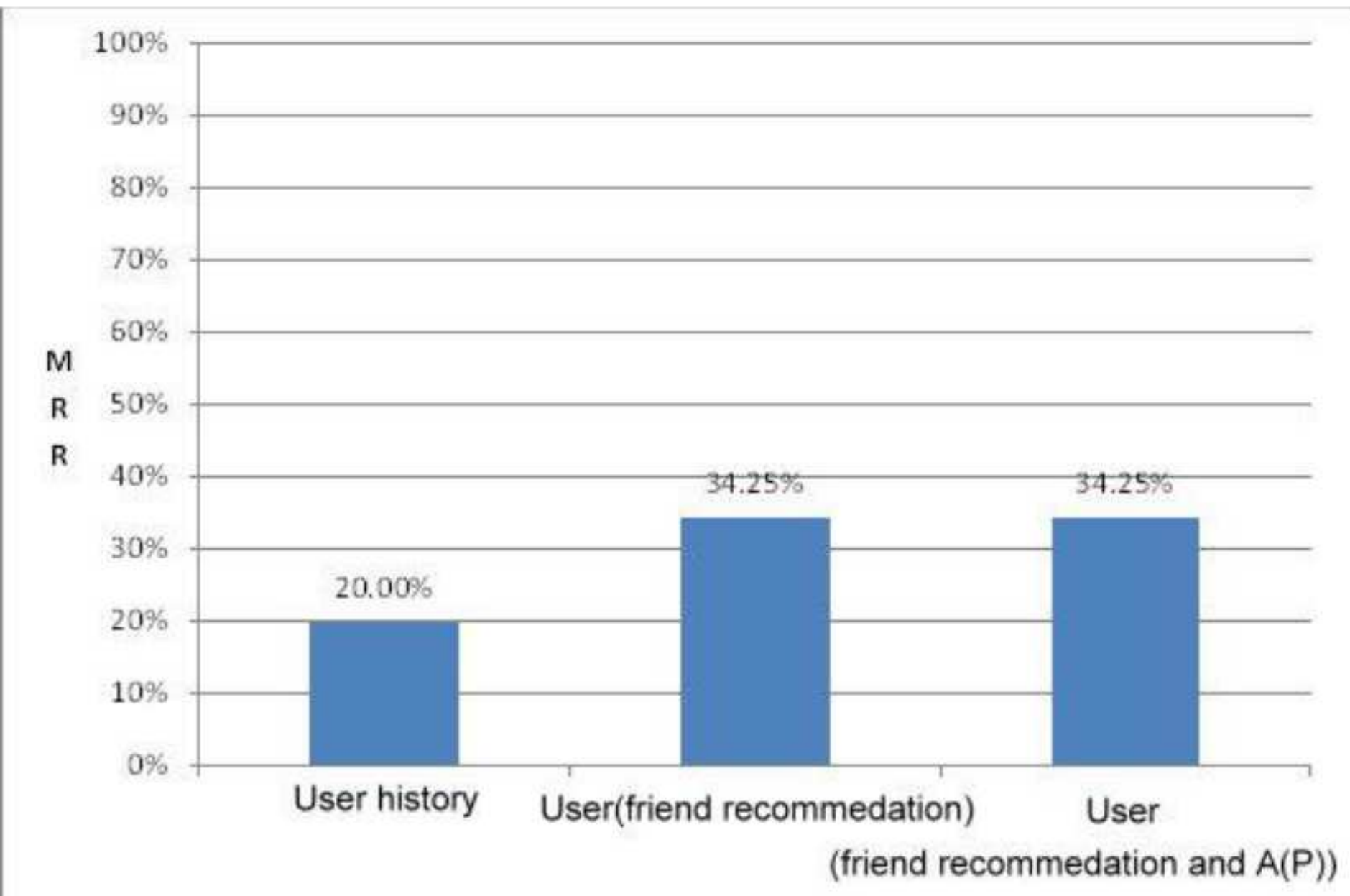

Figure 9

(New User) MRR: User, User (friend recommendation) and User (friend recommendation and $A(P)$ ) 


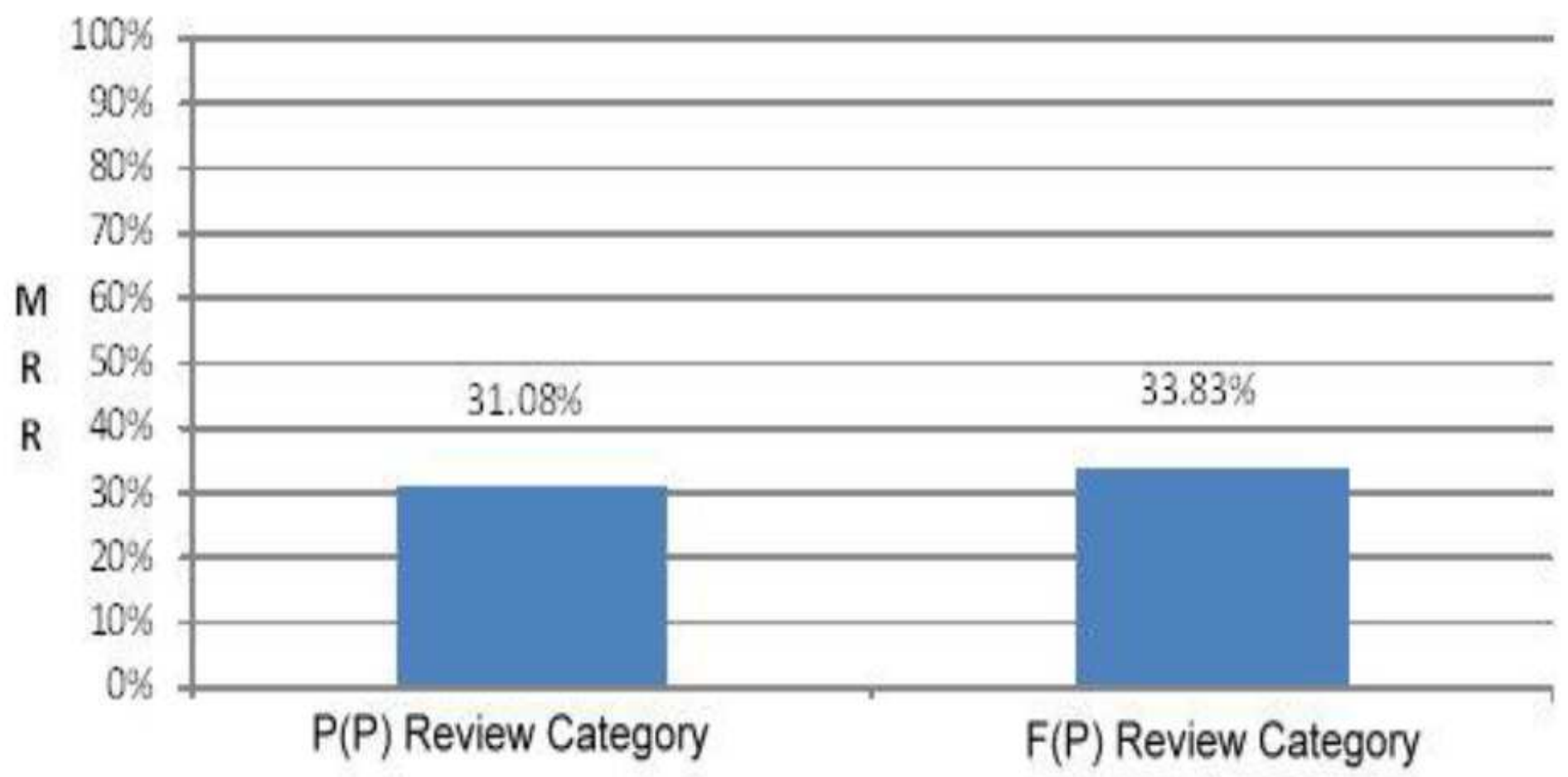

Figure 10

(New User based on $A(P)$ ) MRR comparison between $P(P)$ and $F(P)$ review category 